Revista de Ensino em Artes, Moda e Design

Dossiê 6

A modelagem integrada ao projeto de Moda no âmbito do ensio

\title{
BIÔNICA APLICADA À MODELAGEM VOLTADA À SUSTENTABILIDADE: CONTRIBUIÇÕES DO MODELO MODTHINK
}

\section{Bionics applied to modeling focused on sustainability: contributions of the MODThink model}

\section{Bionics appliqué à la modélisation axée sur la durabilité: contributions du modèle MODThink}

\section{Lucimar de Fátima Bilmaia Emídio}

Karoline Cristyna Ribeiro Bertolino²

\footnotetext{
${ }^{1}$ Doutora e Mestre em Design pela Unesp de Bauru; Especialista em Gestão de Design e em Moda e graduada pela UEL, onde atua como Professora Adjunta e Pesquisadora na área de Design de Moda com ênfase no ensino-aprendizagem de Modelagem do Vestuário. É Líder de Grupo de Pesquisa cadastrado no CNPq na área de Design de Moda; editora da Seção das Revistas Projética e Semina da UEL. E-mail:lucimaremidio@gmail.com/ lattes.cnpq.br/7474139383191422/ orci. org/0000-0003-2094-6779.

${ }^{2}$ Especialista em Direito Civil e Processo Civil ; Bacharel em Direito pela Universidade Estadual de Londrina, onde atualmente é estudante de graduação do Curso Design de Moda ( $5^{\circ}$ período). Membro colaboradora do Projeto de pesquisa intitulado "estudo das ferramentas potencializadoras do ensino-aprendizagem de modelagem", cadastrado na Proppg UEL. E-mail: karolinebertolino@gmail.com. http://lattes.cnpq.br/5890313106315139 / orcid.org/0000-0002-1662-960X
} 


\title{
Resumo
}

O presente estudo apresenta o resultado da aplicação das fases metodológicas do modelo MODThink de Emídio (2018), no contexto de um projeto acadêmico da primeira série do curso de Design de Moda da Universidade Estadual de Londrina. Demonstra como, por intermédio da aplicação da ferramenta de criatividade biônica, foi possível incluir o conceito do projeto na modelagem do produto, além de contribuir para aspectos de produção voltados à sustentabilidade. Contribui-se para estabelecer uma linguagem comum entre a área de design e a de modelagem, a partir do uso de ferramentas de design e técnicas de criatividade, como recursos cognitivos para potencializar as estruturas mentais dos alunos na construção do conhecimento em modelagem.

Palavras-chave: Modelagem do vestuário. Biônica. Modelo MODThink.

\begin{abstract}
This study presents the result of the application of the methodological phases of the MODThink model by Emidio (2018), in the context of an academic project of the first series of the Fashion Design course at the State University of Londrina. It demonstrates how, through the application of the bionic creativity tool, it was possible to include the concept of the project in product modeling, in addition to contributing to aspects of production aimed at sustainability. It helps to establish a common language between the design and modeling area, using design tools and creativity techniques as cognitive resources to enhance students' mental structures in the construction of modeling knowledge.
\end{abstract}

Keywords: Clothing modeling. Bionics. MODThink model.

\section{Résumé}

Cette étude présente le résultat de l'application des phases méthodologiques du modèle MODThink par Emídio (2018), dans le cadre d'un projet académique de la première série du cours de design de mode à l'Université d'État de Londrina. Il montre comment, grâce à l'application de l'outil de créativité bionique, il a été possible d'inclure le concept du projet dans la modélisation des produits, en plus de contribuer aux aspects de la production visant la durabilité. Il aide à établir un langage commun entre le domaine de la conception et de la modélisation, en utilisant des outils de conception et des techniques de créativité comme ressources cognitives pour améliorer les structures mentales des élèves dans la construction des connaissances de modélisation.

Mots-clés: Modélisation de vêtements. Bionique. MODThink modèle. 


\section{INTRODUÇÃO}

O ensino-aprendizagem de modelagem do vestuário, se integrado a processos projetuais de design de moda, não deve se restringir ao uso de instruções de construção de moldes. Implica, necessariamente, trabalhar com um processo de pesquisa que instigue a exploração de ideias e inovações na modelagem do vestuário.

Diante desse contexto Emídio (2018) desenvolveu um modelo voltado ao ensino-aprendizagem de modelagem sob a ótica do design, o qual intitulou MODThink. A autora mesclou três grandes áreas do saber: a da modelagem, da educação e do design.

Pela união destes três campos, o ensino e a aprendizagem da modelagem deixam de ser inertes e exclusivamente instrutivos passando a permitir que o aluno desenvolva um novo modo de pensar a modelagem e não apenas de reproduzi-la. Para a autora, o ensino de modelagem enquanto atividade vinculada a processos projetuais de caráter criativo, deve equacionar sistematicamente o raciocínio do design como uma modalidade de pensamento que inclui a lógica, formação de conceitos e solução de problemas, amparado por métodos, técnicas e ferramentas de design e de criatividade.

Assim, o objetivo deste trabalho é apresentar uma síntese do processo de desenvolvimento e o resultado de um estudo de caso em que o modelo MODThink foi utilizado em um projeto acadêmico universitário. Ao analisar e levantar os principais aspectos envolvidos na delimitação do problema de modelagem, cujo enfoque estava em aplicar o conceito do produto na mesma, identificou-se a possibilidade de utilizar uma ferramenta de criatividade - a biônica - visando criar relação análoga das propriedades do elemento natural com as funções do produto.

O pensamento analógico revela-se apropriado para a conduta de ensino-aprendizagem em modelagem, por contribuir para a transferência de princípios formais; funcionais; ergonômicos e produtivos e para formular hipóteses em diferentes domínios. Favorece a exploração do pensamento lateral do aluno, a comparação de diferentes formas de resolver problemas de modelagem e potencializa a ampliação do seu repertório de conhecimento desta área.

Segundo Baxter (2011) é uma forma de raciocínio em que as propriedades de um objeto são transferidas para um outro diferente, mas com certas propriedades em comum. Nesse contexto, foi possível um olhar para as contribuições do uso da ferramenta de criatividade biônica como técnica criativa com grande potencial de aplicação nos estudos de modelagem. Esta serviu como o eixo a partir do qual se desenvolveu todas as atividades conforme as fases do modelo MODThink: de análise, investigativa, exploratória de verificação e execução da modelagem, considerando o atendimento dos requisitos do projeto e a execução da modelagem que se deu de forma modular, incluindo a graduação e adequação para vestibilidade do produto.

Viu-se no contexto do projeto em questão, a oportunidade e os desafios de se trabalhar a biônica aplicada à modelagem voltada à sustentabilidade, tanto na dimensão técnico-criativa das fases iniciais do referido projeto, quanto na dimensão técnico-criativa que se direciona aos aspectos produtivos do produto em questão.

Assim, a sustentabilidade foi abordada no contexto deste estudo a partir dos 
conceitos apresentados por Birkeland (2002), para o qual os designers são potenciais agentes de mudança, uma vez que as suas decisões podem impedir, alertar, orientar ou influenciar as decisões futuras.

Os resultados mostram o potencial da biônica aplicada à modelagem voltada à sustentabilidade, e as contribuições metodológicas das fases do modelo MODThink para potencializar as estruturas mentais dos alunos na construção do conhecimento em modelagem. Apoia-se em ferramentas de design e técnicas de criatividade como recursos cognitivos para auxiliar nas atividades realizadas em cada fase.

Além disso, considerando que a maioria das ferramentas propostas no referido modelo já são utilizadas por alunos de design de moda para projetar, contribui-se para estabelecer uma linguagem comum entre a área de design e a de modelagem, um modo de pensar e resolver problema de forma análoga em ambas as áreas, fato este que possivelmente ainda não ocorre no ensino tradicional de modelagem dos cursos de design de moda.

\section{DESENVOLVIMENTO}

\subsection{O modelo MODThink no contexto do projeto acadêmico em questão}

O modelo MODThink é composto por 5 fases, sendo que em cada uma delas propõe-se reflexões e análises a serem desenvolvidas, bem como são apresentadas sugestões de ferramentas de design e técnicas de criatividade aplicáveis a cada etapa, como ferramentas cognitivas para o ensino-aprendizagem de modelagem. $O$ modelo parte de uma situação-problema/ questão focal de modelagem e, posteriormente, envolve análise do problema, investigação, exploração, verificação e execução, conforme infográfico da Figura 1. 
BIÔNICA APLICADA À MODELAGEM VOLTADA À SUSTENTABILIDADE:

CONTRIBUIÇÕES DO MODELO MODTHINK

Figura 1: O modelo MODThink
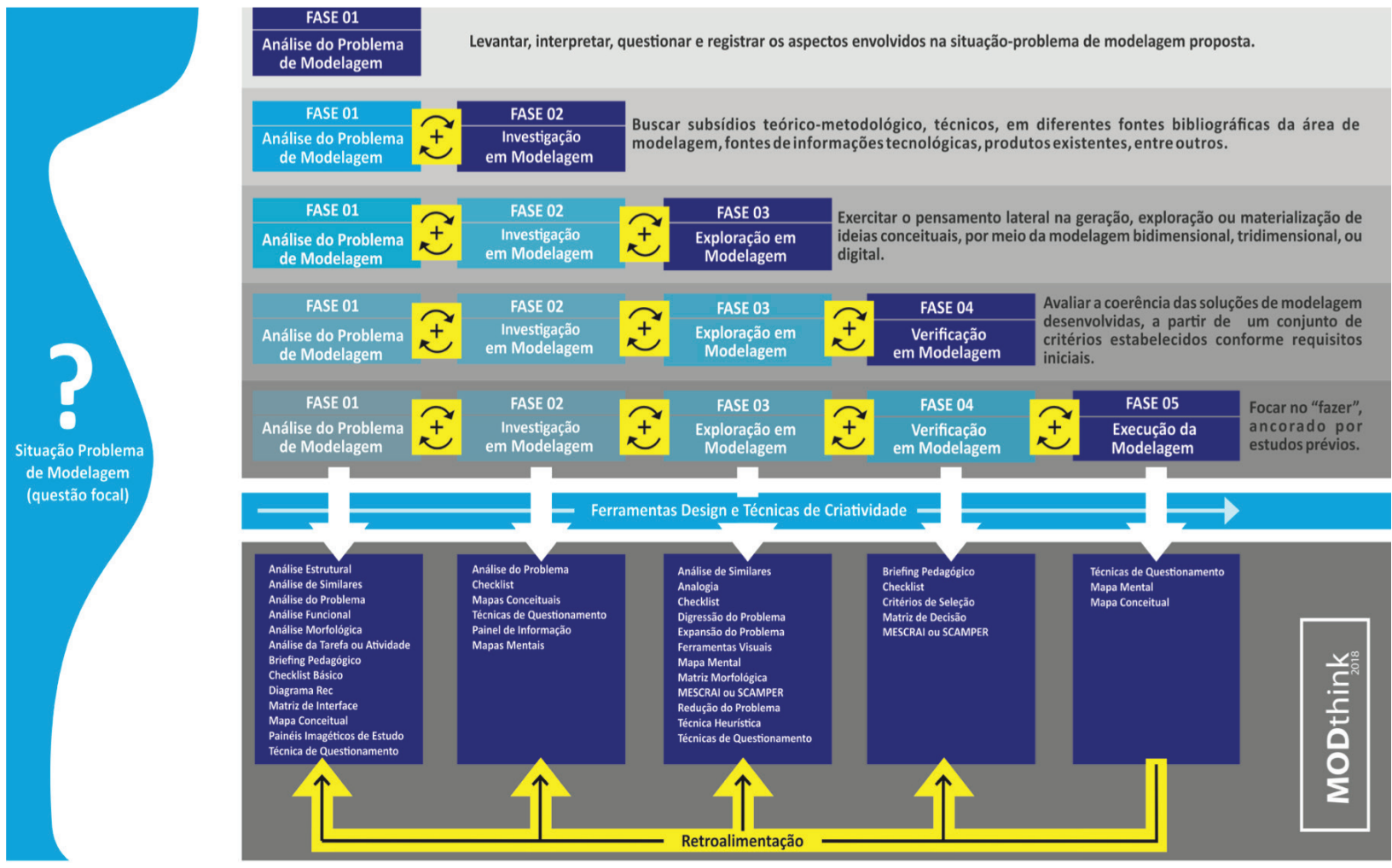

Fonte: Emidio (2018) 
Ao aplicar o referido modelo, o aprendiz o faz sem se afastar totalmente da técnica e de processos cognitivos conhecidos, mas vai além disso, pois concilia estes aspectos com a criatividade/design, isto é, toma por base o modus operandi de se aprender modelagem, mas o processa/desenvolve com o modo de pensar próprio e indispensável à sua futura profissão, a qual prevê flexibilidade, inovação, pensar "fora de padrões", bem como encontrar respostas para os desafios sociais, culturais, econômicos, socioambientais, entre outros. Para Emídio:

Trata-se de um novo modo de pensar o ensino da modelagem, propondo uma renovação na interpretação das disciplinas dessa área que passa a ser pensada integrada à contextos projetuais de design de moda. (EMIDIO, 2018, p. 146)

Ressalta-se que no modelo MODThink não se prevê o uso completo e rígido de todas as fases obrigatoriamente, mas, pelo contrário, e sobretudo para manter coerência com o objetivo a que se propõe, permite-se que haja utilização parcial das fases, bem como o intercâmbio de ferramentas entre elas.

Além disso, possibilita-se a inclusão de outras ferramentas que sejam aplicáveis a distintos contextos, tanto de ensino quanto de aprendizagem. Esta flexibilidade metodológica permitiu adotar a ferramenta biônica, não prevista no rol exemplificativo de ferramentas das fases 1 e 2 do referido modelo, no contexto do projeto acadêmico em questão.

No curso de Design de Moda da Universidade Estadual de Londrina, é proposto aos alunos a realização de projetos que integram todas as disciplinas do ano letivo e que compõe o sistema de avaliação do discente. No segundo semestre do ano de 2018, a aluna autora do projeto apresentado no âmbito deste estudo de caso, por ser colaboradora do projeto de pesquisa onde inicialmente fora apresentado o modelo MODThink, viu a oportunidade de aplicação do referido modelo no contexto do seu projeto integrador.

Importante esclarecer que o projeto acadêmico impôs diversas restrições, pelo qual não foi possível abranger ao máximo o potencial do referido modelo, especialmente na problematização geral do projeto e na primeira etapa de estabelecimento do conceito, pois a base para projetar deveria considerar a vida, família e inspirações do próprio estudante. Ainda, houve restrições quanto ao uso de materiais, sendo permitido apenas o uso de tecido plano de algodão (branco ou cru) e nenhum aviamento já existente, sendo permitido apenas criar aviamentos.

\subsection{Situação-problema de modelagem: questão focal}

Assim como no processo de design, no modelo MODThink parte-se da contextualização e síntese de uma situação-problema. Busca-se trabalhar com

a investigação e exploração da modelagem a partir de uma interação entre fluxos de informações técnico-criativas e técnico-produtivas.

A problematização em modelagem é entendida no contexto do referido modelo como potencialmente significativa para o ensino-aprendizagem de modelagem do 
vestuário. Trata-se de uma perspectiva metodológica de resolução de problemas, amplamente utilizada no design, a qual é concebida como uma atividade construtora de saberes significativos. Para Pozo (1998), ensinar por meio de resolução de problemas é dotar os alunos da capacidade de aprender a aprender, no sentido de habituá- los a encontrar por si só, respostas às perguntas que os inquietam ou que precisam responder, ao invés de esperar uma resposta já elaborada por outros, por livros ou pelo próprio professor.

Ao utilizar do recurso "questão focal" para descrever uma situação-problema, poderá direcioná-la tanto para a dimensão técnico-criativa, quanto para a técnico-produtiva ou ainda abranger ambas as dimensões simultaneamente. Quanto mais elaborada for a questão focal, mais potencialmente eficaz serão os resultados obtidos, uma vez que terá sido mais profundo o mapeamento de busca na fase de investigação em modelagem, bem como a exploração dos conceitos estudados.

Emídio (2018) salienta que apesar dos estudos de modelagem envolverem pensar em fatores tecnológicos, ergonômicos, formais, funcionais, estéticos e produtivos, entre outros, os métodos tradicionais de ensino de modelagem apresentam uma sequencia metodológica centrada no saber-fazer, que não requer do aluno uma problematização que o leve a pensar sobre tais elementos. Contudo, há um entendimento de que é exatamente no desenvolvimento da habilidade de problematizar situações, que reside uma contribuição para estimular as condutas investigativas, exploratórias, verificadoras e executoras em modelagem, e por isso optou-se por este viés metodológico para a área de modelagem.

A cada nova questão focal/problema de modelagem há a possibilidade de causar no aluno possibilidades de realizar outras conexões que lhe trará novos aprendizados. Ou seja, cada nova forma de abordar uma determinada questão de modelagem, podem mudar totalmente a maneira de se interpretar um determinado conteúdo, que poderá ser mesclado com muitas outras áreas do conhecimento diretamente relacionadas ao design de moda.

Daí a importância de abordar sobre as características próprias da forma de pensar no design, voltada à resolução de problemas projetuais, envolvendo, recursos heurísticos, análogos, estilos de pensamentos criativo e lateral e processos mentais diversos aplicados aos estudos de modelagem conforme abordado no contexto metodológico do modelo MODThink.

No tocante ao trabalho em questão, o conceito foi estabelecido e trabalhado a partir da seguinte questão focal: como desenvolver um produto vestível que explore um conceito relacionado com a árvore (planta), as mudanças das estações e adaptações necessárias durante seu ciclo de vida e que seja expresso na modelagem? Tratando-se, portanto, de um projeto intimamente relacionado com a natureza e o meio ambiente.

A questão focal deu suporte de direcionamento para as atividades realizadas nas etapas subsequentes, contribuiu para reunir as informações necessárias para direcionar as atividades na tentativa de criar respostas ao problema, conforme descrito em cada fase do modelo MODThink, a seguir. 


\subsection{Análise do problema e investigação em modelagem}

Do ponto de vista cognitivo, considera-se que nessas duas fases do referido modelo os organizadores prévios devem ser acionados pelos alunos, tendo um caráter de aquecimento para a sequência de atividade a ser desenvolvida, na qual, utilizando de tais mecanismos, o aluno irá estabelecer relações entre proposições técnicas, criativas e produtivas.

Nesta etapa, o principal objetivo foi encontrar uma forma de incluir o conceito na modelagem (questão focal). Assim, conforme objetivos das referidas fases, era imprescindível "levantar, interpretar, questionar e registrar os aspectos envolvidos na situação problema de modelagem proposta" (EMÍDIO, 2018, p. 156-166), bem como buscar embasamento teórico para justificar o resultado.

Considerando a flexibilidade do modelo MODThink e a participação da aluna, coautora deste artigo, no projeto de pesquisa que visava estudar as ferramentas potencializadoras do ensino-aprendizagem de modelagem, ela pôde estabelecer relações entre as ferramentas propostas no MODThink e visualizar a potencialidade da ferramenta biônica para o contexto do seu projeto.

Segundo Pazmino (2015), a biônica é uma técnica criativa que estuda os sistemas naturais dos aspectos relativos à forma, função e materiais, com o objetivo de desenvolver formas, funções e materiais análogos.

(...) A biônica consiste em analisar sistemas naturais, seus princípios e suas características funcionais com o objetivo de identificar princípios de solução, que devidamente adaptados, possam vir a contribuir para solucionar problemas de projeto. Essas adaptações permitem criar formas análogas ou funções análogas. (PAZMINO, 2015, p. 194).

Para Cândido et al.(2006), a biônica é uma ciência multidisciplinar que pesquisa nos sistemas naturais, princípios e/ou propriedades (estruturas, processos, funções, organizações e relações) e seus mecanismos com objetivo de aplicá-los na criação de novos produtos ou para solucionar problemas técnicos existentes nos produtos já concebidos.

Desta forma, a partir do conceito apresentado na contextualização da questão focal, buscou-se encontrar por meio da utilização da ferramenta biônica, um princípio de funcionamento presente na árvore (espécie vegetal) para aplicar em uma vestimenta, oportunidade esta que conduziu ao conceito do fractal. A forma como uma árvore cresce, isto é, seu entroncamento e suas ramificações, obedecem a um padrão geométrico de bifurcação, também conhecido como fractal.

Segundo John Briggs e David Peat:

Os fractais, a geometria das formas irregulares e dos sistemas caóticos são uma maneira de se ver e refletir sobre o paradoxo de complexidade-simplicidade da natureza. Árvores, rios, nuvens e costas podem ser descritos pela geometria fractal. Os fractais matemáticos crescem através de um processo de reciclagem, com os resultados de um ciclo tornando-se os dados de entrada do ciclo seguinte. Em um nível, a complexidade do fractal é uma curiosa ilusão, porque, embora os detalhes da figura possam ser infinitos, ela cresceu de modo simples. (BRIGGS; PEAT, 2000, p. 9) 
A geometria da natureza ou o padrão fractal não é encontrado apenas no crescimento de árvores, mas em diversos outros organismos vivos, podendo apresentar formas fluídas ou estruturadas. Mas em qualquer situação sempre reproduz, em escala menor, a forma concebida anteriormente.

Gleick afirma:

Acima de tudo, fractal significa auto-semelhante. A auto-semelhança é a simetria através das escalas. Significa recorrência, um padrão dentro do outro padrão". Figuras auto-semelhantes são figuras que mesmo ampliando em grande escala não perdem sua forma de visualização. (GLEICK, 1989, p. 97).

Numa árvore o padrão fractal se observa pela bifurcação que ocorre no seu crescimento, repetidamente, desde o entroncamento, ramificação até a estrutura das folhas (Figura 2).

Figura 2: O fractal na árvore

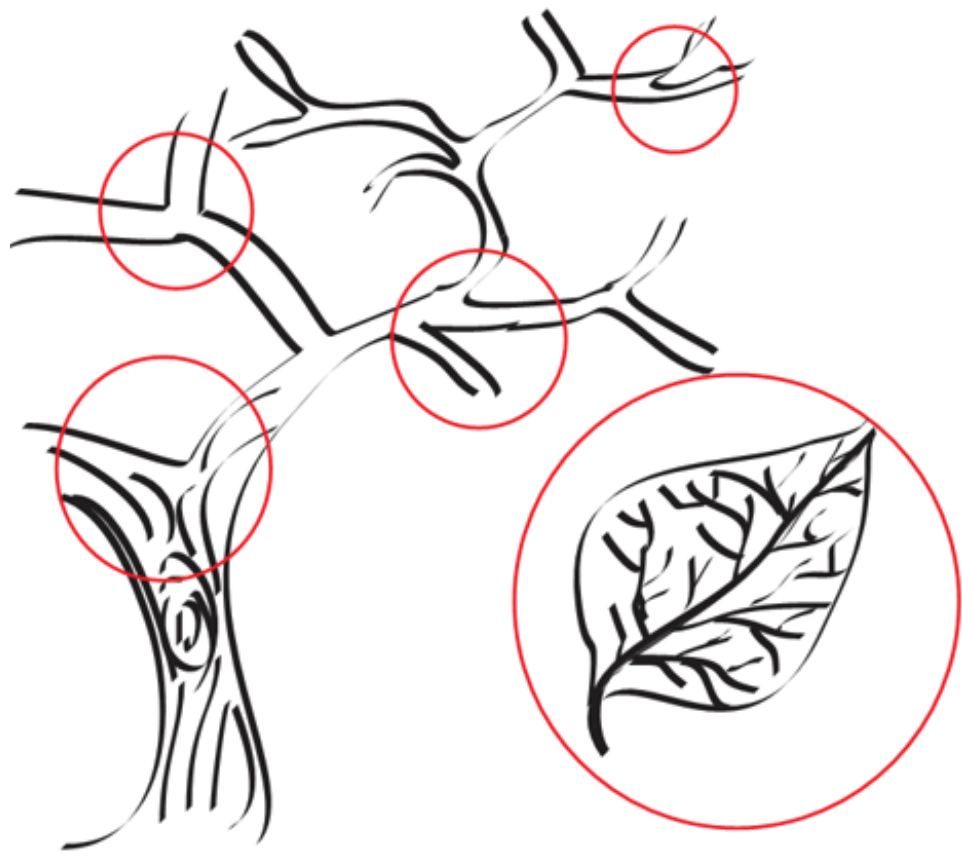

Fonte: Elaborado por Karoline Bertolino (2018)

A árvore consegue ocupar o mínimo de espaço possível e ao mesmo tempo ampliar ao máximo sua copa, para aumentar sua capacidade de absorção de CO2. Segundo Romanha (2009), a disposição fractal da copa das árvores potencializa e maximiza a exposição de uma quantidade enorme de folhas ao sol, permitindo maior eficiência na captação de luz. A disposição fractal das árvores adultas também permite que elas lancem novos ramos durante todo o ano sem que o aumento do perímetro da copa seja perceptível. Então, uma estrutura fractal fornece o máximo de eficiência com o mínimo de ocupação de espaço.

O fractal é uma forma estrutural e padronizada da natureza, por meio da qual consegue organizar, maximizar, reciclar, potencializar e economizar. É simples, mas com grande potencial. No presente estudo, possibilitou-se demonstrar o conceito e, ainda, resolver questões relacionadas com a sustentabilidade. 
Assim, a estrutura fractal foi escolhida como forma de aplicação do conceito da árvore na modelagem do produto, a partir de uma análise do funcionamento da geometria fractal e de como ela é utilizada para solucionar problemas de eficiência e economia da natureza, resultado este obtido com o uso da ferramenta biônica. Por fim, chegou-se à frase-conceito "a vivificante geometria de tudo".

No desenvolvimento do projeto identificou-se a necessidade de optar por uma forma geométrica que expressasse o conceito fractal, desde sua concepção de forma até seu funcionamento (economia e eficiência), contemplando ao máximo possível a busca pela sustentabilidade. A forma geométrica, considerada com maior capacidade de demonstrar o desejado, foi o triângulo, pois:

a) tem o menor número de lados (economizando processos e aumentando encaixes por contorno);

b) a bifurcação da árvore se assemelha a forma triangular;

c) é possível trabalhar os volumes do corpo sem perder a forma triangular original (permanece em evidência), além de modelar o produto sem excesso de folgas no tecido;

d) permite o encaixe e aproveitamento do tecido no risco e corte (se aproximando do minimal waste).

Após a seleção da forma triangular para demonstrar o conceito, a próxima etapa exigiu a exploração em modelagem, isto é, a geração de ideias capazes de aplicar o conteúdo de pesquisa para solução do problema de modelagem proposto.

\subsection{Exploração e verificação em modelagem}

No contexto do modelo MODThink, esta prática relaciona-se à maturação dos elementos do problema de modelagem investigados. Por isto, as atividades realizadas nesta fase visam exercitar o pensamento lateral na geração ou exploração de ideias conceituais, ou materializá-las de forma inovadora considerando os requisitos do projeto. Envolve trabalhar com uma série de processos mentais, podendo utilizar de meios exploratórios bidimensionais, tridimensionais ou computadorizados, sendo que a interpretação das informações investigadas será fundamental, especialmente para os novos conteúdos, com os que o aluno já tem conhecimento. (EMÍDIO, 2018)

Nesta fase, a principal atividade realizada no âmbito do projeto acadêmico foi a geração de alternativas, subsidiada pela ferramenta requisitos de projeto (Quadro 1), e pelos resultados dos paineis de conceito e de expressão do produto. 


\begin{tabular}{|c|c|c|}
\hline REQUISITOS: & OBJETIVOS: & CLASSIFICAÇÃO: \\
\hline \multirow[b]{3}{*}{$\begin{array}{l}\text { Exigências do pro- } \\
\text { jeto integrador }\end{array}$} & Tecido $100 \%$ algodão & Necessário \\
\hline & Não usar aviamentos & Necessário \\
\hline & $\begin{array}{l}\text { Tingimentos e beneficiamentos em geral } \\
\text { serem produzidos/adaptados pelos alu- } \\
\text { nos }\end{array}$ & Necessário \\
\hline \multirow{8}{*}{$\begin{array}{l}\text { Estética agradável/ } \\
\text { visual atrativo }\end{array}$} & Forma geométrica triangular & Necessário \\
\hline & Incluir forma orgânica & Necessário \\
\hline & Peça com recorte aparente & Necessário \\
\hline & Módulo que permite alteração & Desejável \\
\hline & $\begin{array}{c}\text { Demonstrar conceito na modelagem: } \\
\text { árvore, fractal }\end{array}$ & Necessário \\
\hline & Características artesanais & Necessário \\
\hline & Textura/cor não vibrante & Necessário \\
\hline & Aparência casual & Desejável \\
\hline Praticidade & Peça única & Desejável \\
\hline $\begin{array}{l}\text { Funcionalidade/ } \\
\text { ergonomia }\end{array}$ & $\begin{array}{l}\text { Alguns módulos de encaixe que alterem } \\
\text { a funcionalidade }\end{array}$ & Desejável \\
\hline Baixo custo & Redução de custos na produção & Desejável \\
\hline
\end{tabular}

Fonte: Elaborado por Karoline Bertolino (2018)

Os painéis de conceito e expressão do produto (Figuras 3 e 4), que foram desenvolvidos na disciplina de Metodologia Visual, com assessoramento da docente da disciplina ${ }^{1}$, subsidiaram outros aspectos relacionados a geração de alternativas do produto, como a cor, a assimetria, a presença de recorte, a forma estruturada, a forma orgânica (desenho da bifurcação dos galhos), a textura (bordado e artesanato), a ausência de acabamento (naturalidade do tecido) e a costura manual (processo artesanal - considerando o público alvo).

O Painel de Conceito (Figura 3) foi desenvolvido para representar o conceito de Fractal presente especificamente nas árvores. Inserido ao conceito optou-se por trabalhar aspectos que envolvam a geometria, a assimetria e o fluir orgânico presente nos fractais das árvores. A imagem demonstra, simultaneamente, um estado caótico mas, também, esquematizado e rígido.

${ }^{1}$ Professora MSc. Maria Antônia Romão, docente da disciplina de metodologia visual no ano de 2018. 


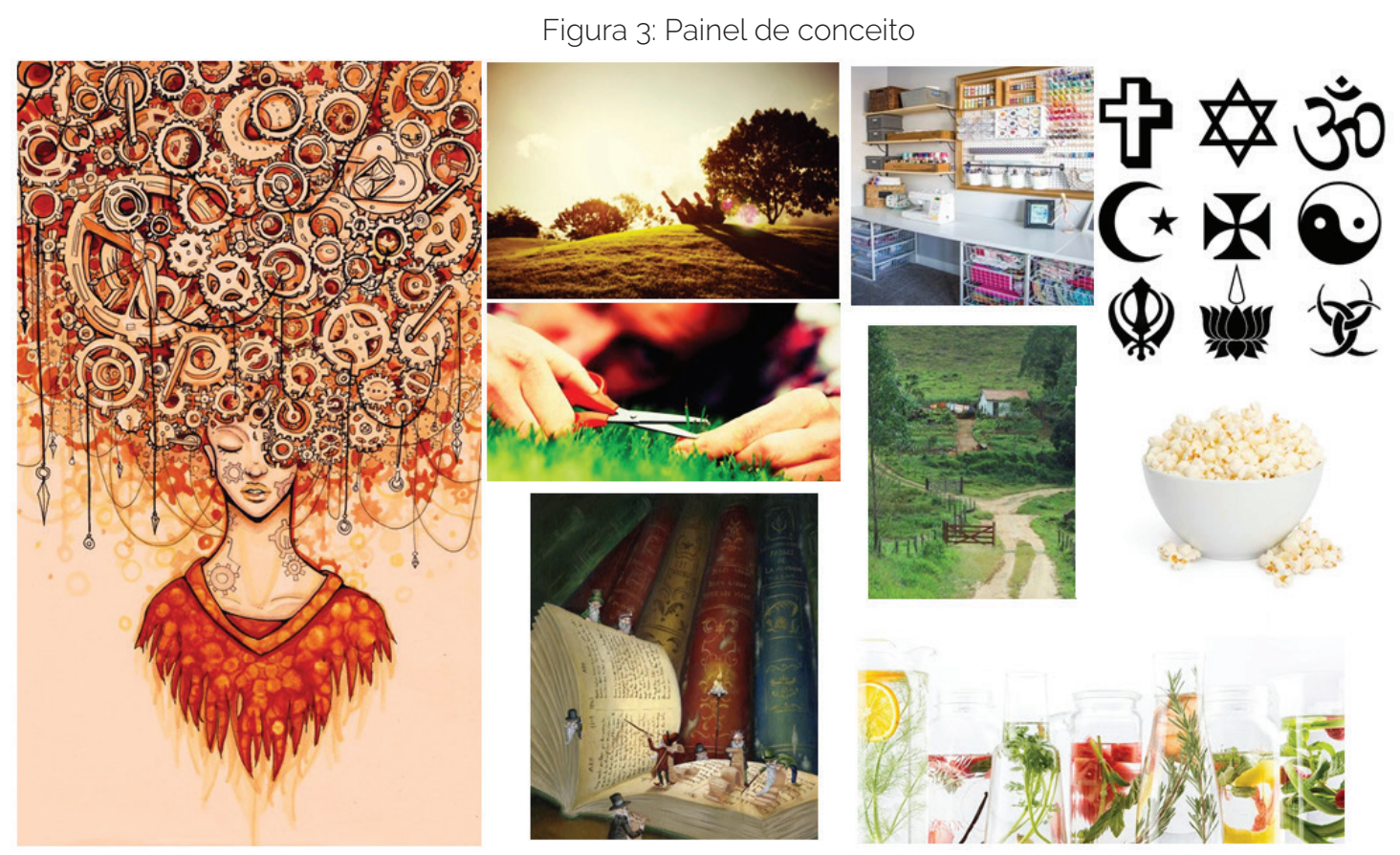

Fonte: Página do site br.pinterest.com²

Neste sentido, o Painel de Conceito busca expressar que o produto deve ser desenvolvido pensando no sincronismo entre formas geométricas e características orgânicas. A partir da imagem, o conceito deve ser traduzido como algo casual, natural, com textura, lúdico, com cores não vibrantes e que reflete as características do publico alvo.

Já Painel de Expressão do Produto (Figura 4) é voltado para expressar características formais do produto. Esse buscou sintetizar a presença de formas triangulares, de recortes, de textura realizada com artesanato trazido pelo bordado, formas orgânicas, presença de transparência, modularidade e assimetria.

Figura 4: Painel de expressão do produto

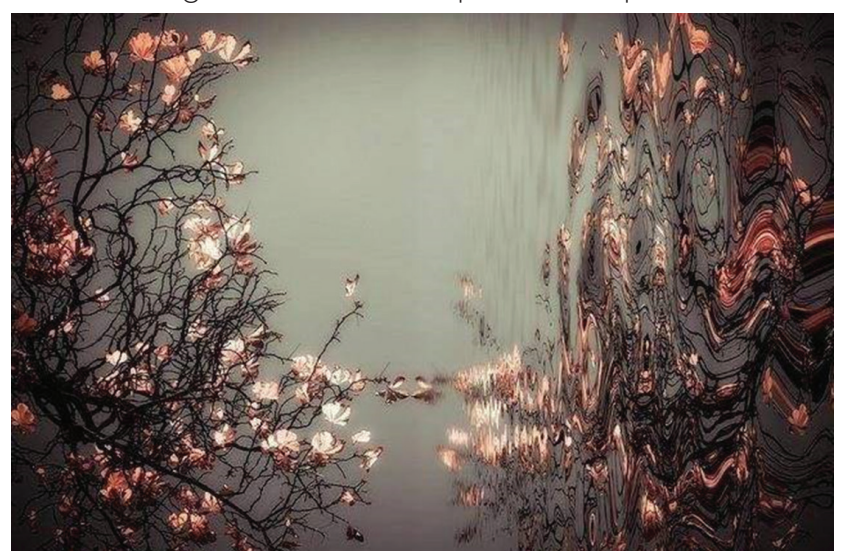

Fonte: Compilação elaborada por Karoline Bertolino(2018)33

Foi desenvolvido também, o Painel de Público Alvo (Figura 5) para demonstrar características de comportamento e preferências do público alvo. O conjunto de

\footnotetext{
${ }^{2}$ Disponivel em <https://br.pinterest.com/pin/692991461399850374/ > Acesso em: 23 Fev. 2020. 3 Montagem a partir de imagens coletadas no site br.pinterest.com. Disponivel em < https:// br.pinterest.com/karolinebertolino/mv/> acesso em 23 Fev. 2020.
} 
imagens foi compilado da internet com a intenção de representar maturidade de ideais, busca por vida no campo e/ou em contato com a natureza, perfeccionismo, estima por artesanato, personalidade eclética com adaptabilidade e ludicidade (incluindo aspectos fantasiosos e infantis).

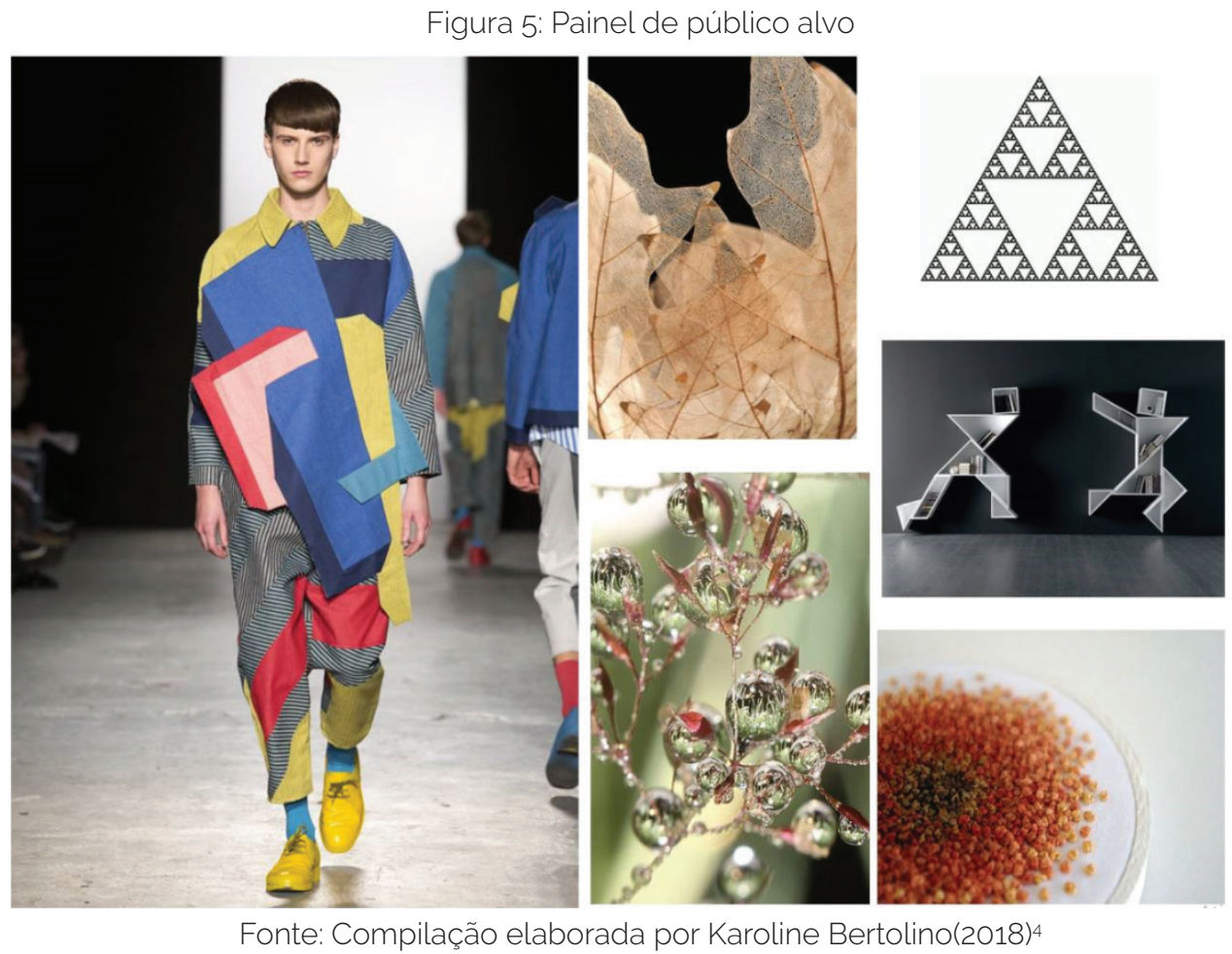

As alternativas geradas totalizaram 48 e foram geradas a partir de três moldes (Figura 6), todos em forma de triângulos equiláteros classificados como grande, médio e pequeno, com as medidas de $20 \mathrm{~cm}, 10 \mathrm{~cm}$ e $5 \mathrm{~cm}$, respectivamente, considerando a escala reduzida de 1:2.

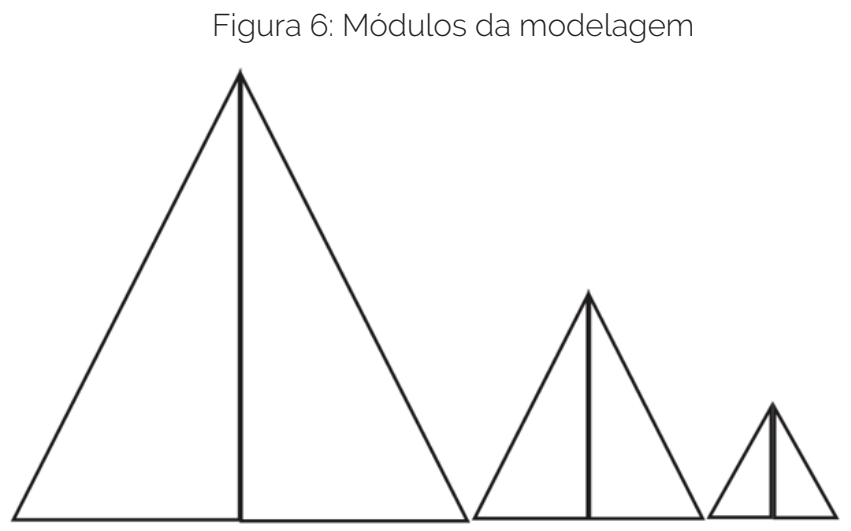

Fonte: Elaborado por Karoline Bertolino (2018)

Para a geração de alternativas adotou-se ainda o conceito sistêmico de sustentabilidade apresentado por Amador (2007), um conceito relacionado com a continuidade dos aspectos econômicos, sociais, culturais e ambientais da sociedade humana. Sendo assim, procurou-se por processos menos impactantes, com valorização da

${ }^{4}$ Montagem a partir de imagens coletadas no site br.pinterest.com. Disponivel em < https:// br.pinterest.com/karolinebertolino/mv/> acesso em 23 Fev. 2020. 
mão de obra artesanal (sustentabilidade social), encaixes dos referidos moldes em busca do minimal waste e beneficiamentos que não prejudicassem o reaproveitamento do tecido e linhas no upcycling.

Observa-se que a geração de alternativas realizada (Figura 7) sob tais perspectivas, demandou contemplar os conhecimentos de modelagem tanto da dimensão técnico-criativa como técnico-produtiva, com assessoramento das docentes da disciplina de modelagem plana e tridimensional ${ }^{5}$. Os estudos exploratórios foram realizados em manequim tamanho 40 e em escala reduzida de 1:2.

Figura 7: Processo de geração de alternativas da aluna

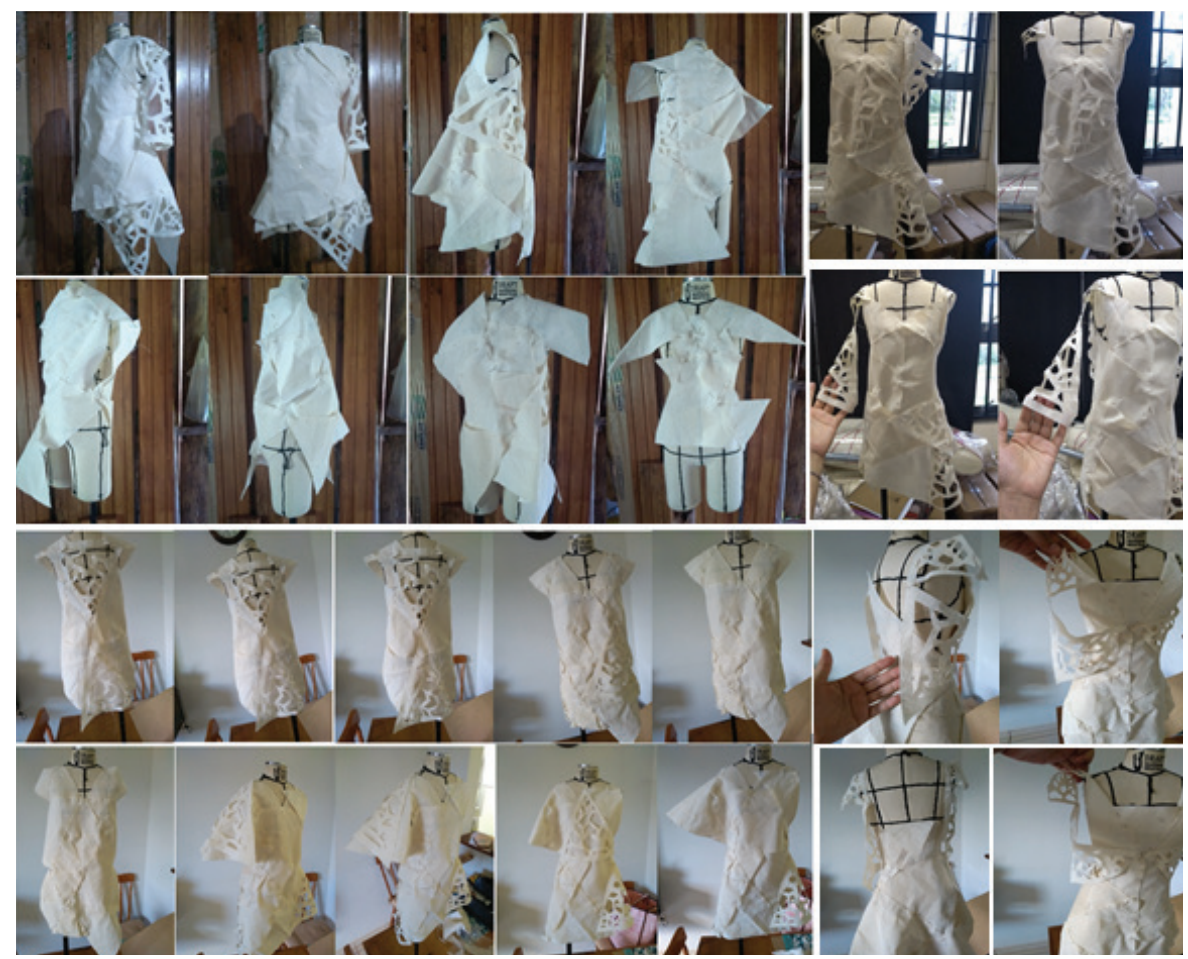

Fonte: Elaborado por Karoline Bertolino (2018)

O encaixe, que protagonizou, em vias de produção, a busca pela sustentabilidade, foi realizado considerando o padrão abaixo (Figura 8):

Figura 8: Encaixe

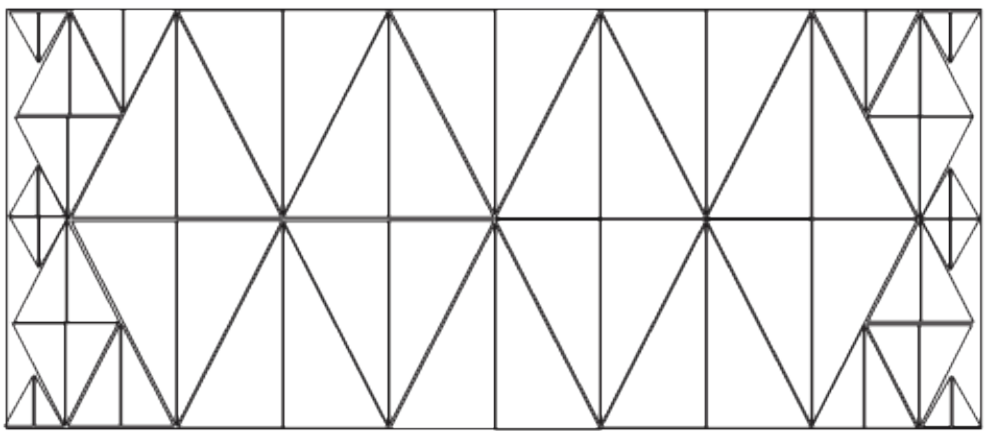

Fonte: Elaborado por Karoline Bertolino (2018)

\footnotetext{
5 Prof. Dra.Patrícia de Mello Souza, docente da disciplina de modelagem tridimensional no ano de 2018. Prof. Dra. Lucimar de F. Bilmaia Emídio, docente da disciplina de modelagem plana no ano de 2018.
} 
Após a etapa de exploração em modelagem, conforme o modelo MODThink foi necessário estabelecer critérios para selecionar as melhores ideias e para finalizar o processo de criação do produto por meio da modelagem. Trata-se da fase denominada verificação em modelagem.

Considerando que no processo de projeto a fase de seleção de ideias é um processo mais sistemático e rigoroso que a geração destas, Emídio (2018) transpõe o mesmo princípio metodológico para o contexto do referido modelo por meio desta fase, a qual relaciona-se com a análise crítica das soluções propostas, a partir dos estudos investigativos-exploratórios previamente realizados.

(...) Contudo, a viabilidade técnica-produtiva deve ser avaliada de forma sistêmica, atendendo também aos requisitos estéticos-formais, ergonômicos e funcionais delimitados no contexto de cada estudo. Assim, os estudos já realizados nas fases anteriores e meios oferecidos ao aluno para avaliar, julgar e tomar decisões quanto a viabilidade construtiva e produtiva dos produtos, servirão ainda de suporte ao aprendizado significativo de modelagem. (EMÍDIO, 2018, p. 172).

Sendo assim, para cada alternativa gerada foi aplicada a ferramenta critérios de seleção considerando os requisitos de projeto para que, por fim, pudesse selecionar as 5 alternativas mais pontuadas e, dentre as finalistas, escolher uma com base na ferramenta matriz de decisão. Os critérios de seleção constam no Quadro 2.

Quadro 2: Critérios de seleção

\begin{tabular}{|c|c|}
\hline \multirow{2}{*}{ ASPECTOS } & CRITÉRIOS \\
\hline \multirow{4}{*}{ Estética } & Boa continuidade \\
\cline { 2 - 2 } & Semelhança dos elementos \\
\cline { 2 - 3 } & Pregnância do conceito \\
\cline { 2 - 2 } & Casual \\
\cline { 2 - 2 } Configuração & Assimetria \\
\cline { 2 - 2 } & Modularidade \\
\cline { 2 - 2 } & Harmonia de encaixe \\
\hline \multirow{2}{*}{ Ergonomia } & Interação homem-produto \\
\hline \multirow{3}{*}{ Fabricação } & Estrutura geométrica e orgânica \\
\cline { 2 - 2 } & Aproveitamento do tecido \\
\cline { 2 - 2 } & Poucos processos \\
\hline
\end{tabular}




\begin{tabular}{|c|c|}
\hline \multirow{2}{*}{ Inovação } & Aumento do ciclo de vida \\
\cline { 2 - 2 } & Alteração de partes do produto \\
\hline
\end{tabular}

Fonte: Elaborado por Karoline Bertolino (2018)

A análise realizada a partir da ferramenta matriz de decisão, permitiu selecionar a alternativa a ser confeccionada (Figura 9), com base nos seguintes resultados: maior pregnância do conceito, possibilidade de alteração das partes do produto, ser assimétrico e casual, cumprir com todas as regras estipuladas para o projeto integrador acadêmico, e possuir maior inovação.

Figura 9: Alternativa selecionada para produto
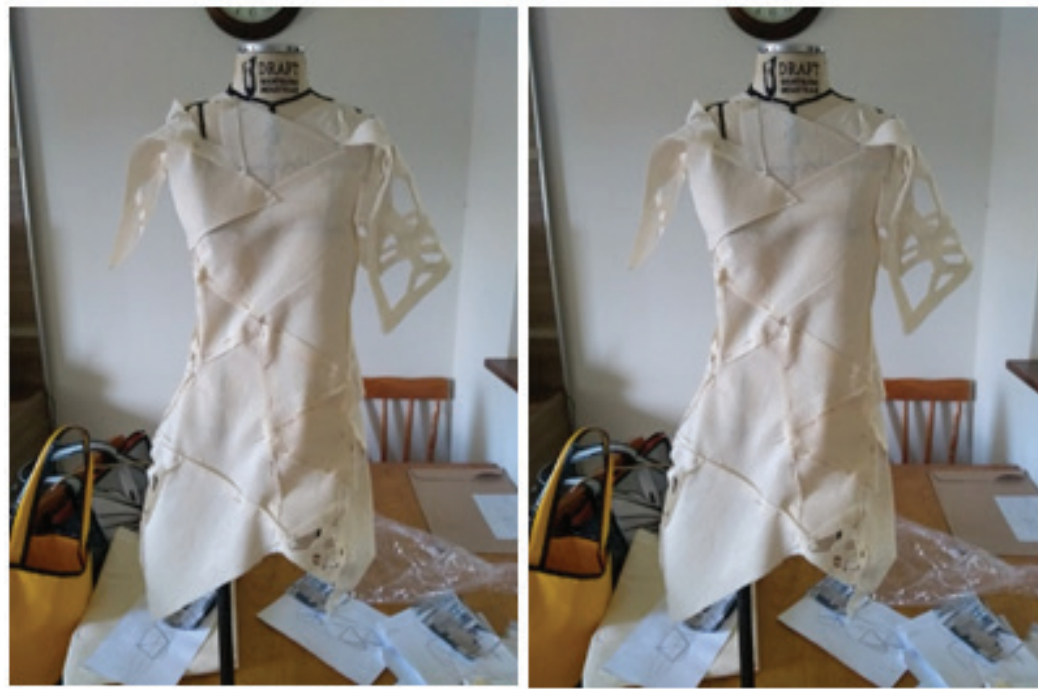

Fonte: Elaborado por Karoline Bertolino (2018)

\subsection{Execução em modelagem}

O processo de construção da modelagem com base nas fases do modelo MODThink prevê o fazer embasado em estudos prévios e ancorado por atividades de análise, investigação, exploração e verificação realizadas nas fases anteriores deste modelo. Segue a lógica construtivista de uma atividade mental auto estruturante, a qual possibilita ao aluno estabelecer relações, ser autônomo no pensar, decidir e agir, constituindo-se como sujeito ativo de seu aprendizado.

Assim, o primeiro passo realizado nesta etapa foi a graduação dos moldes, inserção de margens de costuras e de folga para vestibilidade. Uma vez que os moldes foram previamente executados no tamanho 40 e em escala 1:2, estes deveriam ser produzidos no manequim tamanho 50 e em escala natural, para que o produto pudesse ser utilizado pela aluna na ocasião da apresentação e defesa do seu projeto acadêmico integrador.

Considerando que a modelagem era composta por três moldes em formato de triângulo de tamanhos diferentes, a graduação ocorreu da seguinte forma: 
a) primeiramente verificou-se que o maior triângulo tinha exatamente a medida de ombro a ombro do manequim tamanho 40 em meia escala;

b) realizou-se o cálculo para tamanho real (2 vezes o tamanho das laterais do triângulo);

c) verificou-se a diferença de $3 \mathrm{~cm}$ na medida de ombro a ombro entre o manequim tamanho 40 e o tamanho 50 ;

d) calculou-se em porcentagem, o quanto de aumento deveria ser aplicado ao triângulo, utilizando da técnica de questionamento: se $40 \mathrm{~cm}$ corresponde a 100\%, qual percentual equivale à $43 \mathrm{~cm}$ ?

e) a resposta foi 107\%, porcentagem esta aplicada aos 2 triângulos menores, para conseguir graduar todos na mesma proporção para o tamanho 50;

f) assim os triângulos grande, médio e pequeno, com as medidas em escala reduzida, tamanho 40 que mediam $20 \mathrm{~cm}, 10 \mathrm{~cm}$ e $5 \mathrm{~cm}$, respectivamente, passaram a medir $43 \mathrm{~cm}, 21,4 \mathrm{~cm}$ e 10,7 cm, quando graduados para manequim tamanho 50.

Após a graduação de cada triângulo, optou-se pelo acréscimo de $1 \mathrm{~cm}$ de folga de vestibilidade nas laterais de cada um, além do acréscimo de $1 \mathrm{~cm}$ para costura. Considerando estas margens, o produto foi confeccionado para o manequim tamanho 50.

No processo de confecção, optou-se novamente pela busca da sustentabilidade, sendo que cada triângulo da peça teve suas laterais costuradas à mão (Figura 10) com linha de bordado e poderia, portanto, ser destacado do restante da peça, uma vez que, cada corte/pedaço de linha costurou apenas uma lateral de um triângulo, repetindo-se o procedimento para todos os módulos triangulares. Na Figura 10 observa-se a realização da costura manual unindo cada lateral dos triângulos de forma individualizada.

Figura 10: Costura manual dos módulos triangulares
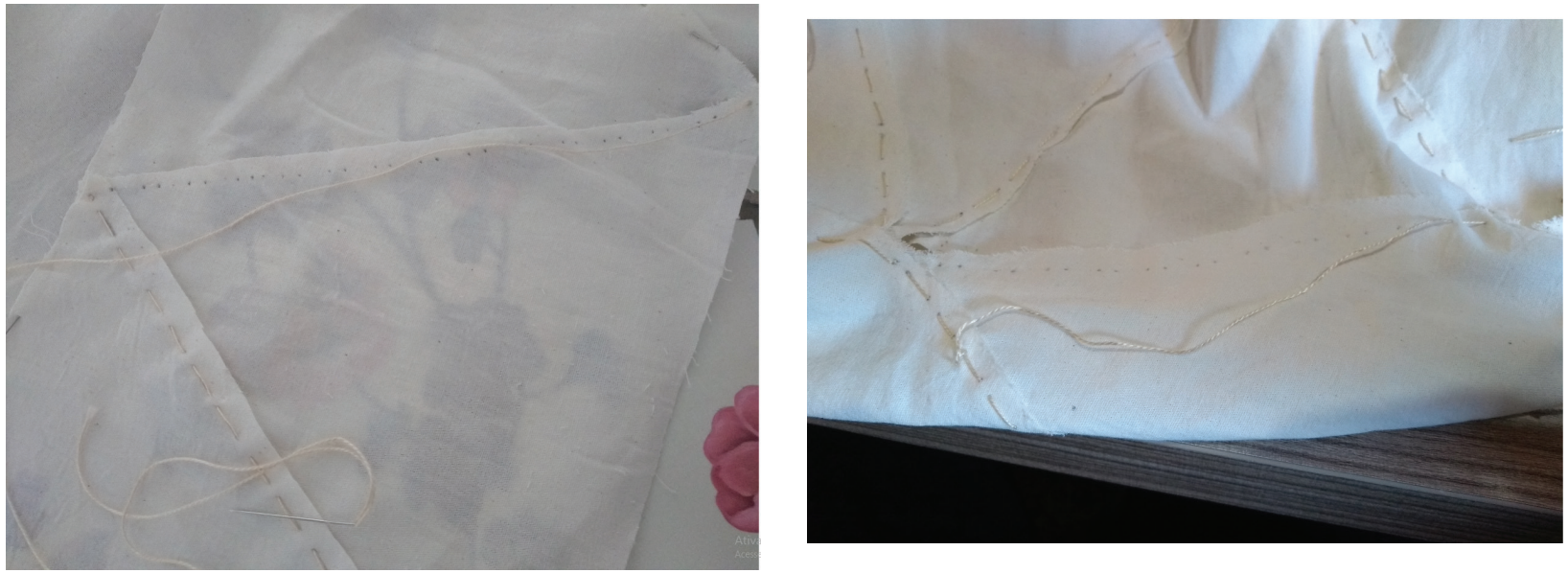

Fonte: Elaborado por Karoline Bertolino (2018) 
Dessa forma, é possível trocar, alterar um módulo triangular sem prejudicar o restante da peça, seja porque o módulo substituído estragou ou para renovação do aspecto estético da peça. Tal procedimento oportuniza o prolongamento do ciclo de vida do produto e garante o descarte apenas de módulos necessários, diminuindo a geração de resíduos.

Além disso, para o beneficiamento do produto utilizou-se apenas da técnica de bordado livre, manual, favorecendo a mão de obra artesanal e permitindo inclusão social.

Ao mesmo passo, a técnica do bordado permite o desmanche do mesmo, com reaproveitamento das linhas para outros setores de artesanato ou reciclagem de matéria prima e, por fim, permite que o tecido suporte do bordado seja reciclado, visto que não teve seu fio tingindo ou alterado por qualquer outro tipo de beneficiamento, conforme se observa na Figura 11.

Figura 11: Registro do produto final no corpo da aluna

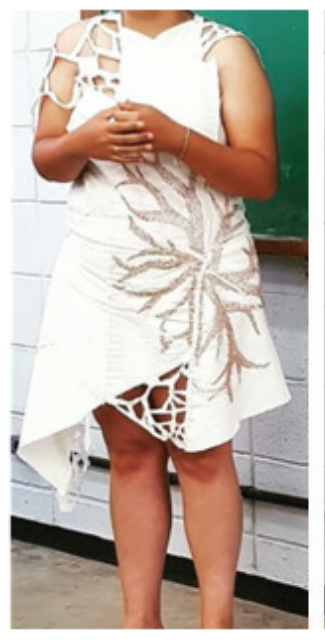

\section{CONCLUSÃO}
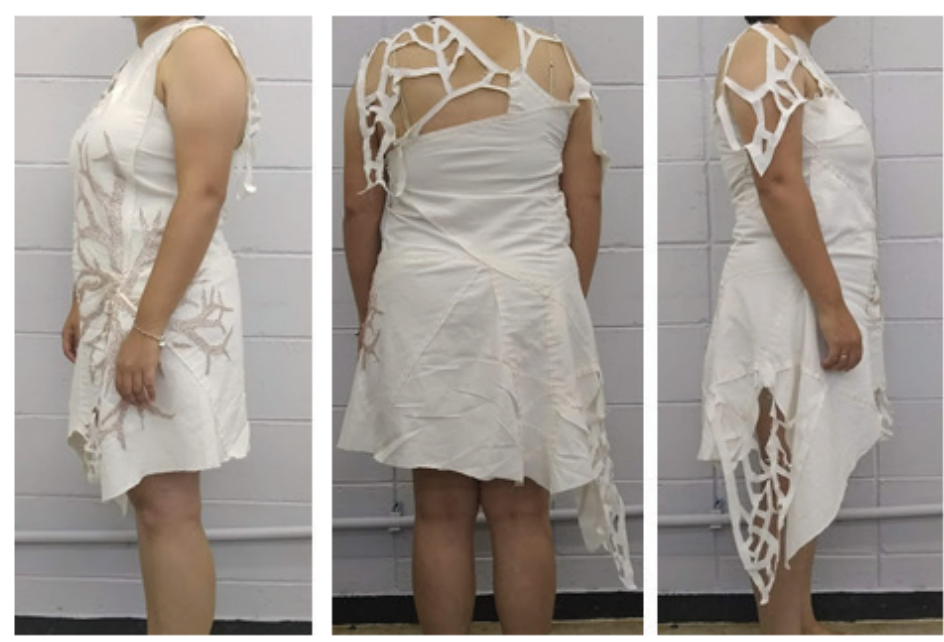

O modelo MODThink oportunizou à discente um olhar totalmente novo para explorar a modelagem. Permitiu que a aluna reconhecesse não apenas o caráter técnico e produtivo da modelagem, enquanto um fazer instrucional, mas também seu aspecto criativo, inovador e abstrato, a partir do emprego das ferramentas de design e técnicas de criatividade.

O uso da biônica, como cerne do trabalho e base para o desenvolvimento do pensamento produtivo voltado à sustentabilidade, alcançou o objetivo de retratar o conceito de "árvore" no vestuário, abrangendo desde sua forma até seus aspectos subjetivos/psicológicos, pois aproximou o produto do público-alvo desde a aplicação do conceito no produto (modelagem e forma estética) até a sua forma de confecção.

Assim, verifica-se que o modelo apresentado por Emídio (2018), contribui metodologicamente na formação de designers de moda que buscam por soluções inovadoras visando atender a necessidades humanas (físicas, psicológicas, socioambientais, socioculturais, entre outras), uma vez que procura utilizar os recursos de 
modelagem disponíveis de forma inovadora.

Não há aqui, a pretensão de descartar o uso de novas tecnologias e saberes, mas, demonstrar que há a necessidade de mesclá-los com os já conhecidos e, principalmente, de potencializar o uso de conhecimentos e de técnicas que já fazem parte do dia-a-dia do designer de moda, mas que ainda não foram totalmente explorados, como por exemplo, o uso da biônica e demais ferramentas de design e técnicas criativas, aplicadas à soluções de problema de modelagem.

Desta forma, espera-se contribuir para que trabalhos futuros desta área possam relacionar os elementos abordados no contexto deste artigo, na projetação de produtos do vestuárió.

\section{REFERÊNCIAS}

AMADOR, M. B. M. Sustentabilidade: constatação de uma prática, ainda, abissal em ambiente rural. Palestra proferida no III Fórum Ambiental da Alta Paulista, Tupã-SP, 4 set. 2007.

BAXTER, Mike. Projeto de produto: guia prático para o design de novos produtos. São Paulo: E. Blucher, 2011.

BIRKELAND, J. Design for sustainability: a soucebook of integrated eco-logical solutions. London: Earthscan Publications, 2002.

BRIGGS, John; PEAT, F. david. Sabedoria do caos. 2000. Disponível em: <https://teoriadacomplexidade.com.br/wp-content/uploads/2017/02/A-SabedoriaDoCaos.pdf> . Acesso em: 29 de maio de 2019.

CÂNDIDO, Luís H. A.; SANTOS, Sandra S.; MARQUES, André C.; VIEGAS, Maurício da S.; KINDLEIN, Wilson Jr.. Desenvolvimento de elementos de junção/fixação a partir de estudo da Biônica. Paraná, PR: $7^{\circ}$ Congresso brasileiro de pesquisa e desenvolvimento em design, 2006.

EMÍDIO, Lucimar de Fátima Bilmaia. Modelo MODThink: o pensamento de design aplicado ao ensino-aprendizagem e desenvolvimento de competências cognitivas em modelagem do vestuário. Tese (Doutorado). Universidade Estadual Paulista (UNESP). São Paulo, 2018.

GLEICK, James. CAOS: a criação de uma nova ciência. 17 ed., Rio de Janeiro: Campus, 1989.

PAZMINO, Ana Verônica. Como se cria: 40 métodos para design de produto. São Paulo: Blucher, 2015.

\footnotetext{
${ }^{6}$ Versão do artigo revisada por Marly Emídio. Licenciada em Letras Vernáculas, pela Universidade
} Estadual de Londrina. E-mail: marlyemidio@sercomtel.com 
POZO, J. I. (Org). A solução de problemas não aprender a resolver, resolver para aprender. Porto Alegre: Artmed, 1998.

ROMANHA, W. S. Fractais na natureza. 30 jun. 2009. Disponível em: < http://microsintonias.blogspot.com/2009/06/fractais-na-natureza.html>. Acesso em: 29 de maio de 2019.

Recebido em: 28/02/2020

Aceito em: 16/04/2020 